\title{
Optimization of the Runner Numerical Design Dimensions using the Simulation Program
}

\author{
Jan Majernik$^{1}$, Stefan Gaspar $^{2}$, Martin Podaril ${ }^{1}$, Jan Kolinsky ${ }^{1}$ \\ ${ }^{1}$ Institute of Technology and Business in České Budějovice, Okružní 517/10, 370014 České Budějovice, Czech Republic, \\ E-mail: majernik@mail.vstecb.cz \\ ${ }^{2}$ The Technical University of Košice, Faculty of Manufacturing Technologies with a seat in Prešov, Bayerova 1, 08001 \\ Prešov, Slovak Republic, E-mail: stefan.gaspar@tuke.sk
}

The proper design of the gating system including the tempering and venting of the mold significantly influences the final quality of the casting and economize the costs of the foundries. The initial numerical design of the gating system is often sufficient for creating of the documentation for the mold design, but without the practical experience of the designer, it does not reveal the hidden problem emerging from the melt flow through the gating system as well as the temperature and gas mode of the mold. The contribution is dedicated to the optimization of the runner dimensions determined by the numerical calculation. The theoretical part presents the methodology, based on which the gating system was designed for a particular type of the pressure casting. The experimental part is dedicated to the influence of the cross sectional area of the runner on the change of the melt temperature before entering the ingate. It was assumed that the larger runner cross section gives the melt greater volume and heat capacity and thus the melt enters the ingate with the higher temperature. The obtained temperature results are then compared witht he melt flow rate values, based on which an optimal sulotion for the runner design dimensions is determined.

Keywords: High Pressure Die Casting, Runner, Construction, Technological Parameters

\section{Introduction}

The principles for gating system design are compiled in the Czech Republic standard ČSN 22 8601. The gating system dimensions are based on the dimensional and volumetric parameters of the casting, on the basis of which the gate cross section is determined. The calculation of the cross sectional area of the runners is based on the gate area. This standard specifies the initial parameters for determination of the dimensions of the gate: the filling time of mold cavity and the gate melt velocity. The minimum ratio of the gate area and the cross section of the channel before entering the ingate is shown for the design of the gating channels. The recommended parameter values are stated at the permissible intervals delimited by the maximum and minimum permissible values. [1] The possibility of correct selection is limited by the constructor's experience and thus implements the risk of error calculation. The error created by selection of the input parameters in the design by selecting from the prescribed interval is eliminated by the calculation formulated by J. F. Wallace and E. A. Herman in the Gating Manual, issued under the auspices of NADCA. [2] In the monography Influence of Structure Adjustment of Gating System of Casting Mold upon the Quality of Die Cast (Gašpár, 2017, Lüdenscheid: RAM - Verlag), authors drew on the above-mentioned methods of designing the gating systems and established the design methodology according to which the gating system for casting has been designed and put under the investigation. [3]

The results presented int he contribution were based on the design solution of the gating sytem for casting of the gear pump thrust face presented on Fig. 1.

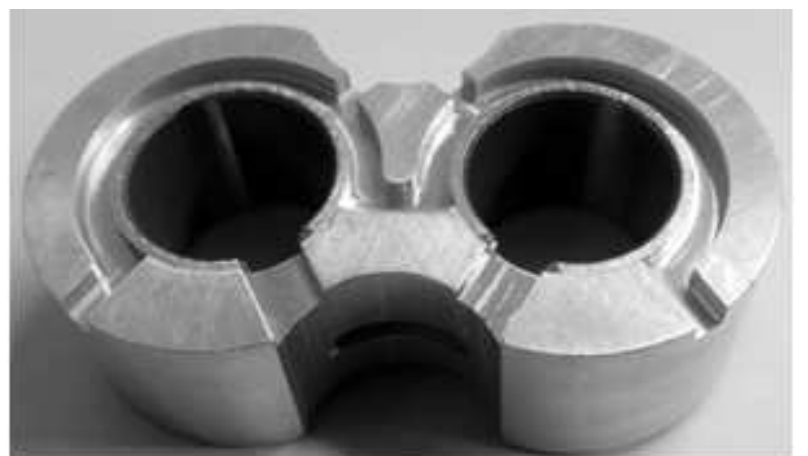

Fig. 1 Thrust face of the gear pump

The design of the gating system was realized based on the methodology described in the monography [3] according to Gašpar et al. The numerical design, considered as a referenced, was subsequently modified by reducing the cross section of the runners in order to find out the most advantageous solution of the ratio between the temperature capacity inside the melt volume and the melt flow rate. NovaFlow\&Solid simulations were performed on the individual equivalents of the solution.

\section{Methodology of the gating system design}

The first parameter required to determine the gate area is the filling time of the mold cavity. The best method of the calculation was the NADCA method. The empirically derived formula $\mathrm{i}$ sused to determine the filling time of mold cavity:

$$
t=K \cdot\left\{\frac{T_{Z}-T_{L I K}+S . Z}{T_{L I K}-T_{f}}\right\} \cdot h_{c h}
$$


Where:

$\mathrm{t}$ - filling time [s]

$\mathrm{TZ}$ - melt temperature in the gate $\left[{ }^{\circ} \mathrm{C}\right]$,

TLIK - temperature of the liquidus $\left[{ }^{\circ} \mathrm{C}\right]$,

$\mathrm{Tf}$ - mold temperature $\left[{ }^{\circ} \mathrm{C}\right]$,

$\mathrm{S}$ - permissible percent of the melt solidification at the end of the mold cavity filling [\%],

$\mathrm{Z}$ - the particle conversion factor related to the solidification range $\left[{ }^{\circ} \mathrm{C} / \%\right.$,

$\mathrm{K}$ - the empirically derived constant associated with the conductivity of the mold $[\mathrm{s} / \mathrm{m}]$,

$\mathrm{hch}-$ characteristic thickness of the casting wall [m], $\mathrm{hch}=0,002 \mathrm{~m}$.

Part of the equation in brackets expresses the temperature dependencies and processes within the mold.
The constant $K$ acquires the values:

- $0,0312 \mathrm{~s} / \mathrm{mm}$ between the AISI P-20 steel (preliminary hardened nitrated steel for plastic injection molds) and zinc alloys,

- 0,0252 s/mm between the AISI H-13 steel (steel and chromium alloys) and the AISI H-21 steel (alloys of steel, chromium and tungsten) and magnesium alloys,

$-0,0346 \mathrm{~s} / \mathrm{mm}$ between the AISI H-13 and AISI H-21 steels, aluminium and brass alloys,

- 0,0124 s/mm between tungsten and magnesium, zinc, aluminum and brass alloys.

The following Tab. 1 shows the permissible values for solidification depending on the thickness of the wall.

Tab. 1 The permissible values for solidification of the material depending on the thickness of the wall

\begin{tabular}{|c|c|c|c|}
\hline \multirow{2}{*}{$\begin{array}{c}\text { Thickness of the wall, } \\
\mathrm{mm}\end{array}$} & \multicolumn{2}{|c|}{ Permissible values for material solidification $S[\%]$} \\
\cline { 2 - 4 } & Aluminum & Magnesium & Zinc \\
\hline$<0,8$ & 5 & 10 & 15 \\
\hline $0,8-1,25$ & $5-25$ & $5-15$ & $10-20$ \\
\hline $1,25-2$ & $15-35$ & $10-25$ & $15-30$ \\
\hline $2-3$ & $20-50$ & $20-35$ & $20-35$ \\
\hline
\end{tabular}

Constant $\mathrm{Z}$ acquires values:

$4,8^{\circ} \mathrm{C} / \%$ for ASTM 360, 380 a 384 aluminum alloys, all subeutectonic alloys of AlSi $(\mathrm{Cu} / \mathrm{Mg})$ containing less than $12 \%$ of silicon,

$5,9{ }^{\circ} \mathrm{C} / \%$ for ASTM 390 aluminum alloys, aboveeutectonic alloys of $\mathrm{AlSi}(\mathrm{Cu} / \mathrm{Mg})$,

$3,7^{\circ} \mathrm{C} / \%$ for magnesium alloys,

$3,2{ }^{\circ} \mathrm{C} / \%$ for zinc alloys 12 and 27 ,

$2,5^{\circ} \mathrm{C} / \%$ for zinc alloys 3,5 and 7 ,

$4,7{ }^{\circ} \mathrm{C} / \%$ for brass.

If the mold cavity filling time is know, based on the character of the alloy and the diameter of the plunger, it is possible to determine the melt velocity in the ingate according to:

$$
v_{z}=\frac{m_{O}}{\rho \cdot t \cdot d_{p} \cdot 0,785}
$$

Where:

$v_{z}-$ velocity of the melt flow in ingate $\left[\mathrm{m} . \mathrm{s}^{-1}\right]$

$\rho$ - alooy density $\left[\mathrm{kg} \cdot \mathrm{m}^{-3}\right]$

$d_{p}$ - diameter of the filling chamber of the machinepriemer plniacej komory stroja [m],

0,785 - constant to:

The gate area of Variant 1 was determined according

$$
S_{Z}=\frac{G}{\rho \cdot t \cdot v_{z}}=0,7606 \mathrm{~cm}^{2}
$$

Where:

$G$ - the sum of the casting weight and the flow rates

Once the basic starting parameters have been determined, it is possible to determine the dimensional characteristics of the ingate. The width of the ingate is dependent on the radius of the casting and is determined according to the method of projection of the ingate connection to the casting according to:

$$
a=\frac{2 \cdot \pi \cdot R \cdot \alpha}{360}=\frac{2 \cdot \pi \cdot R \cdot 60}{360}=\frac{\pi \cdot R}{3}
$$

$a$ - ingate width [m]

$\alpha$ - the angle defining the length of the ingate $\left[^{\circ}\right]$, constantly acquires the value $\alpha=60^{\circ}$

$R$ - the radius of the cylindrical surface of the casting to which the ingate is attached [m].

Ingate height is determined according to:

$$
b=\frac{S_{Z}}{a}
$$

The cross section of the runner has the shape of a trapezoid with a wall inclination of $10^{\circ}-15^{\circ}$ (Fig. 2). The ratio of height and average width of the channel should be within the ratio $1: 1$ to $1: 3$. usually its $1: 2$.

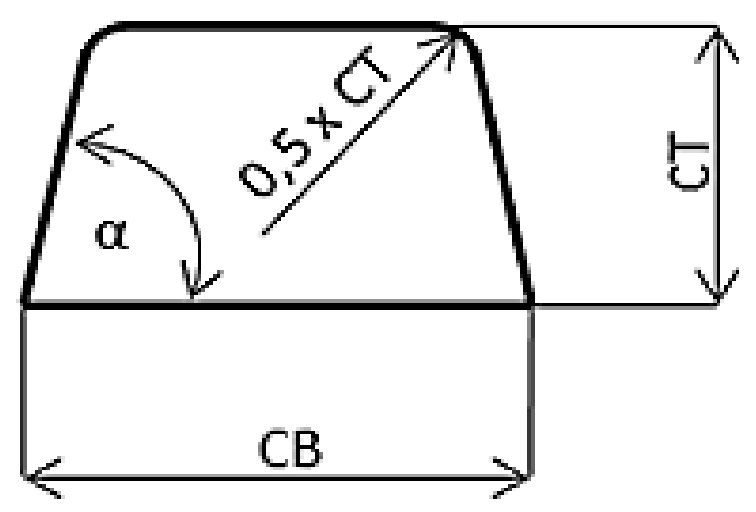

Fig. 2 Cross section of runner [3]

The calculation of the runner depends on the multiplicity of the mold. The influence on the runner 
cross section has mostly the runner branching, while it should be valid that if the runner is split by branching, its overall cross section should be increased by 5 to $30 \%$ after each split from the gate to the bisquit.

The calculation itself is done by designing the diameters of the runners in the opposite direction than the ingate.

The cross section of the runner is determined according to:

$$
S_{K}=C B \cdot C T-C T^{2} \cdot \operatorname{tg}\left(90^{\circ}-\alpha\right)=2 \cdot C T^{2}-C T^{2} \cdot \operatorname{tg}\left(90^{\circ}-\alpha\right) \Rightarrow C T=\sqrt{\frac{S_{K}}{2-\operatorname{tg}\left(90^{\circ}-\alpha\right)}}
$$

Where:

$\alpha$ - angle of the runner walls gradient

Depending on the defined runner height: The runner width:

$$
C B=2 . C T
$$

The branching runner surface can be determine according to:

$$
S_{K Z}=\left(S_{K 1}+S_{K 2}+\ldots+S_{K N}\right) \cdot k
$$

Where:

Tab. 2 Dimensional characteristics of gating system

\begin{tabular}{|l|l|l|l|}
\hline MAIN RUNNER & ADJOINING RUNNER \\
\hline Parameter & Value & Parameter & Value \\
\hline Cross section area $/ S_{K}$ & $831.9^{\wedge} 10^{-6} \mathrm{~m}^{2}$ & Cross section area $/ S_{K V}$ & $440^{\wedge} 10^{-6} \mathrm{~m}^{2}$ \\
\hline Height / $C T$ & $15.94^{\wedge} 10^{-3} \mathrm{~m}$ & Height $/ C T$ & $15.94^{\wedge} 10^{-3} \mathrm{~m}$ \\
\hline Width / $C B$ & $56.46^{\wedge} 10^{-3} \mathrm{~m}$ & Width $/ C B$ & $31.88^{\wedge} 10^{-3} \mathrm{~m}$ \\
\hline Length / $l$ & $100^{\wedge} 10^{-3} \mathrm{~m}$ & Length $/ l_{V}$ & $593.11^{\wedge} 10^{-3} \mathrm{~m}$ \\
\hline Angle of the walls / $\alpha$ & $75^{\circ}$ & Angle of the walls $/ \alpha$ & $75^{\circ}$ \\
\hline Roundness intensity & Roundness intensity & $8^{\wedge} 10^{-3} \mathrm{~m}$ \\
\hline INGATE & $8^{\wedge} 10^{-3} \mathrm{~m}$ & & \\
\hline Gate area $/ S_{Z}$ & $54.96^{\wedge} 10^{-6} \mathrm{~m}^{2}$ & \\
\hline Gate length $/ a$ & $19.82^{\wedge} 10^{-3} \mathrm{~m}$ \\
\hline Gate height $/ b$ & $2.77^{\wedge} 10^{-3} \mathrm{~m}$ \\
\hline
\end{tabular}

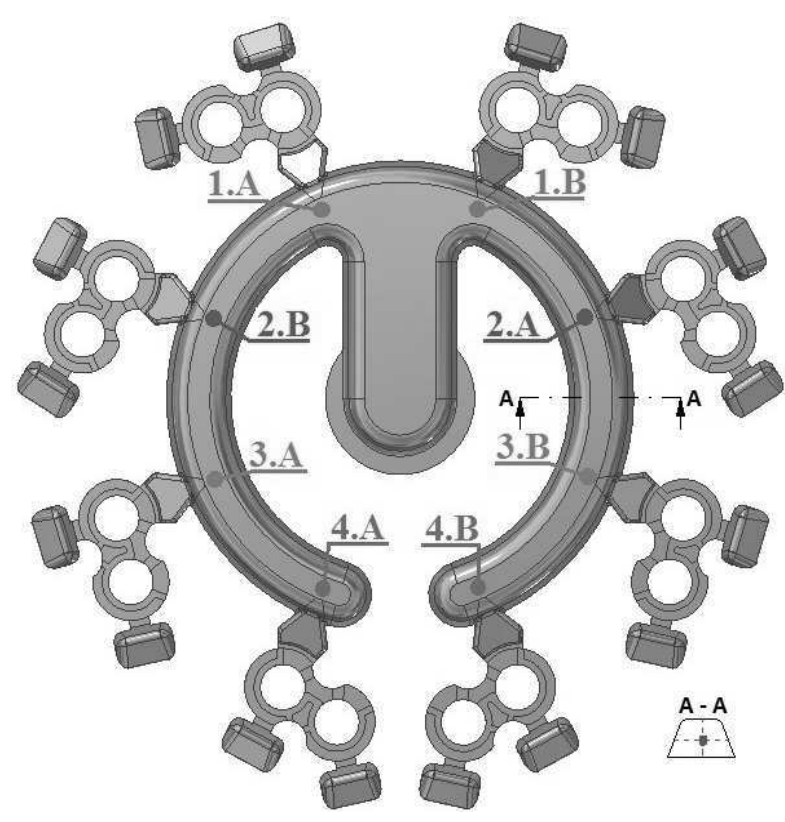

Fig. 3 Measuring points in the gate system
$S_{K Z}$ - the runner area after the unification,

$S_{K N}$ - the area of n-th joint runner,

$k$ - coefficient of the runner cross section increase ( 5 $-30 \%)$. [3]

\section{Characteristics of the gating system and mea- suring points}

Based on the above described methodology of the gating system design, a reference gating system was constructed. In $\boldsymbol{T a b}$. 2 the basic dimensional characteristics of proposed gating system are stated.

$n$ - the number of the castings into which the melt is d through the runner.

Due to recommended ratio of the ingate and the me roundness of the runner and for the runner height is defined the formula: 
Tab. 3 Examined parameters of gating system

\begin{tabular}{|c|c|c|c|c|}
\hline \multicolumn{5}{|c|}{ RUNNER DIMENSIONS } \\
\hline & & Runner area $S\left[\mathrm{~mm}^{2}\right]$ & Runner width $C B[\mathrm{~mm}]$ & Runner height $C T[\mathrm{~mm}]$ \\
\hline \multirow{2}{*}{$\begin{array}{l}\text { 1. VK440 } \\
\text { Reference }\end{array}$} & VK & 440.098 & 31.88 & 15.94 \\
\hline & HK & 831.9 & 56.46 & 15.94 \\
\hline \multirow[t]{2}{*}{ 2. VK420 } & VK & 420 & 30.62 & 15.94 \\
\hline & $\mathrm{HK}$ & 792.45 & 53.98 & 15.94 \\
\hline \multirow[t]{2}{*}{ 3. VK400 } & $\mathrm{VK}$ & 400 & 29.36 & 15.94 \\
\hline & $\mathrm{HK}$ & 754.72 & 51.62 & 15.94 \\
\hline \multirow[t]{2}{*}{ 4. VK380 } & $\mathrm{VK}$ & 380 & 28.10 & 15.94 \\
\hline & $\mathrm{HK}$ & 716.98 & 49.24 & 15.94 \\
\hline \multirow[t]{2}{*}{ 5. VK360 } & VK & 360 & 26.84 & 15.94 \\
\hline & $\mathrm{HK}$ & 679.25 & 46.88 & 15.94 \\
\hline \multirow[t]{2}{*}{ 6. VK340 } & VK & 340 & 25.58 & 15.94 \\
\hline & $\mathrm{HK}$ & 641.51 & 44.52 & 15.94 \\
\hline \multirow[t]{2}{*}{ 7. VK320 } & VK & 320 & 24.35 & 15.94 \\
\hline & HK & 603.77 & 42.15 & 15.94 \\
\hline \multicolumn{5}{|c|}{ AVERAGE MELT FLOW LENGTH $l_{S}[\mathrm{~mm}]$} \\
\hline Measuring point & & \begin{tabular}{l|l}
$l_{S 1}$ & \\
\end{tabular} & $l_{S 3}$ & $l_{S 4}$ \\
\hline 1.A / 1.B & & 139.25 & ---------- & ---------- \\
\hline $2 . \mathrm{A} / 2 . \mathrm{B}$ & & ---------- & ---------- & ---------- \\
\hline $3 . \mathrm{A} / 3 . \mathrm{B}$ & & ---------- & 296.25 & ---------- \\
\hline 4.A / 4.B & & ---------- & ---------- & 374.75 \\
\hline
\end{tabular}

*VK - adjoining runner

*HK - main runner

\section{Analysis of the melt temperature change}

Because of the relevance of the results, the setting of technological parameters during the casting cycle for all models was maintained at a constant level. The temperature of the melt in the pressing chamber was maintained at $T_{T}=610^{\circ} \mathrm{C}$, the mold temperature was $T_{f}=$ $200^{\circ} \mathrm{C}$ and in the runned, the constant mass flow was set on $Q_{m}=55,446 \mathrm{~kg} \cdot \mathrm{s}^{-1}$. In practice, the melt temperature by entering the mold cavity should be at least 10 to $20^{\circ} \mathrm{C}$ higher than the temperature at which the melt begins to crystallize. If the hot mel tis cast into a cold mold which has been insufficiently insulated with a suitable lubricant, the surface layers of the mold will be heavily stressed and the mold will wear out sooner. The low melt temperature on the casting is manifested by the formation of cold joints, weldings and map surfaces. For this reason, the temperature of the individual measuring points was monitored. In $\boldsymbol{T a} \boldsymbol{b} . \mathbf{4}$ and $\boldsymbol{T} \boldsymbol{a} \boldsymbol{b} . \mathbf{5}$, the melt temperature values in the individual runners is shown. The temperature of the firstly oxidized face of the mel tis evaluated at the first contact with the measuring point and the melt temperature at the end of the filling.

Tab. 4 The temperature of the melt flow front

\begin{tabular}{|l|l|l|l|l|l|l|l|}
\hline TEMPERATURE OF THE MELT FLOW FACE $\boldsymbol{T}_{\boldsymbol{f} \boldsymbol{m}}\left[{ }^{\circ} \mathbf{C}\right]$ \\
\hline \multirow{3}{*}{ Point } & cross section of runner \\
\cline { 2 - 9 } & VK440 & VK420 & VK400 & VK380 & VK360 & VK340 & VK320 \\
\hline $\mathbf{1 . /} / \mathbf{T}_{\mathbf{1}}$ & 599.17 & 587.665 & 581.925 & 587.975 & 592.18 & 587.07 & 588.375 \\
\hline $\mathbf{2 .} / \mathbf{T}_{\mathbf{2}}$ & 583.77 & 592.895 & 587.135 & 584.83 & 584.975 & 583.73 & 585.275 \\
\hline $\mathbf{3 .} / \mathbf{T}_{\mathbf{3}}$ & 567.115 & 572.48 & 577.015 & 568.19 & 567.525 & 559.83 & 566.925 \\
\hline $\mathbf{4 .} / \mathbf{T}_{\mathbf{4}}$ & 572.255 & 575.08 & 572.265 & 575.93 & 581.025 & 580.75 & 580.24 \\
\hline
\end{tabular}

Tab. 5 Temperature of the melt at the end of the filling

\begin{tabular}{|l|l|l|l|l|l|l|l|}
\hline \multicolumn{2}{|l|}{ TEMPERATURE OF THE MELT AT THE END OF THE FILLING $\boldsymbol{T}_{\text {ef }}\left[{ }^{\circ} \mathbf{C}\right]$} \\
\hline \multirow{3}{*}{ Point } & cross section of runner \\
\cline { 2 - 9 } & VK440 & VK420 & VK400 & VK380 & VK360 & VK340 & VK320 \\
\hline $\mathbf{1 . /} \mathbf{T}_{\mathbf{1}}$ & 604.99 & 605.065 & 605.99 & 605.222 & 605.52 & 606.275 & 605.32 \\
\hline $\mathbf{2 .} / \mathbf{T}_{\mathbf{2}}$ & 604.03 & 603.975 & 603.695 & 604.3 & 604.37 & 604.19 & 604.045 \\
\hline $\mathbf{3 . /} \mathbf{T}_{\mathbf{3}}$ & 597.045 & 596.87 & 599.26 & 597.665 & 599.425 & 599.335 & 599.26 \\
\hline $\mathbf{4 . /} \mathbf{T}_{\mathbf{4}}$ & 582.35 & 584.06 & 585.575 & 585.855 & 587.225 & 586.155 & 585.665 \\
\hline
\end{tabular}

Prior to the simulation, it was assumed that a larger cross section of the runner gives the melt greater volume and heat capacity and thus the melt enters the gate even at a higher temperature. This premise was disproved by the simulation. It has been shown that the highest temperatures at the measuring points were shown by the 
variation of the gating system No.5, designated as a VK360.

Alloy EN AC 47100 was selected for casting, which liquidus temperature is according to the material list $T_{\text {liq }}$ $=590^{\circ} \mathrm{C}$. The simulations showed, that the condition of value of minumum melt overheat while entering the mold cavity 10 to $20^{\circ} \mathrm{C}$ above the liquidus is reached only at the runner lengths $l_{S 1}$ and $l_{S 2}$. For a better visualisation of the temperature change during the filling of the mold cavity, the graph was constructed (Fig. 4). The graph shows the development of the temperature in runner No. 5 -VK360, which evinced the highest temperatures in the measuring points, and the temperatures in the runners No.1 - VK440 and No.7 - VK320, which are characterized by boundry values of the runner cross section. The development of the temperatures are plotted at measuring points 1 and 4 .

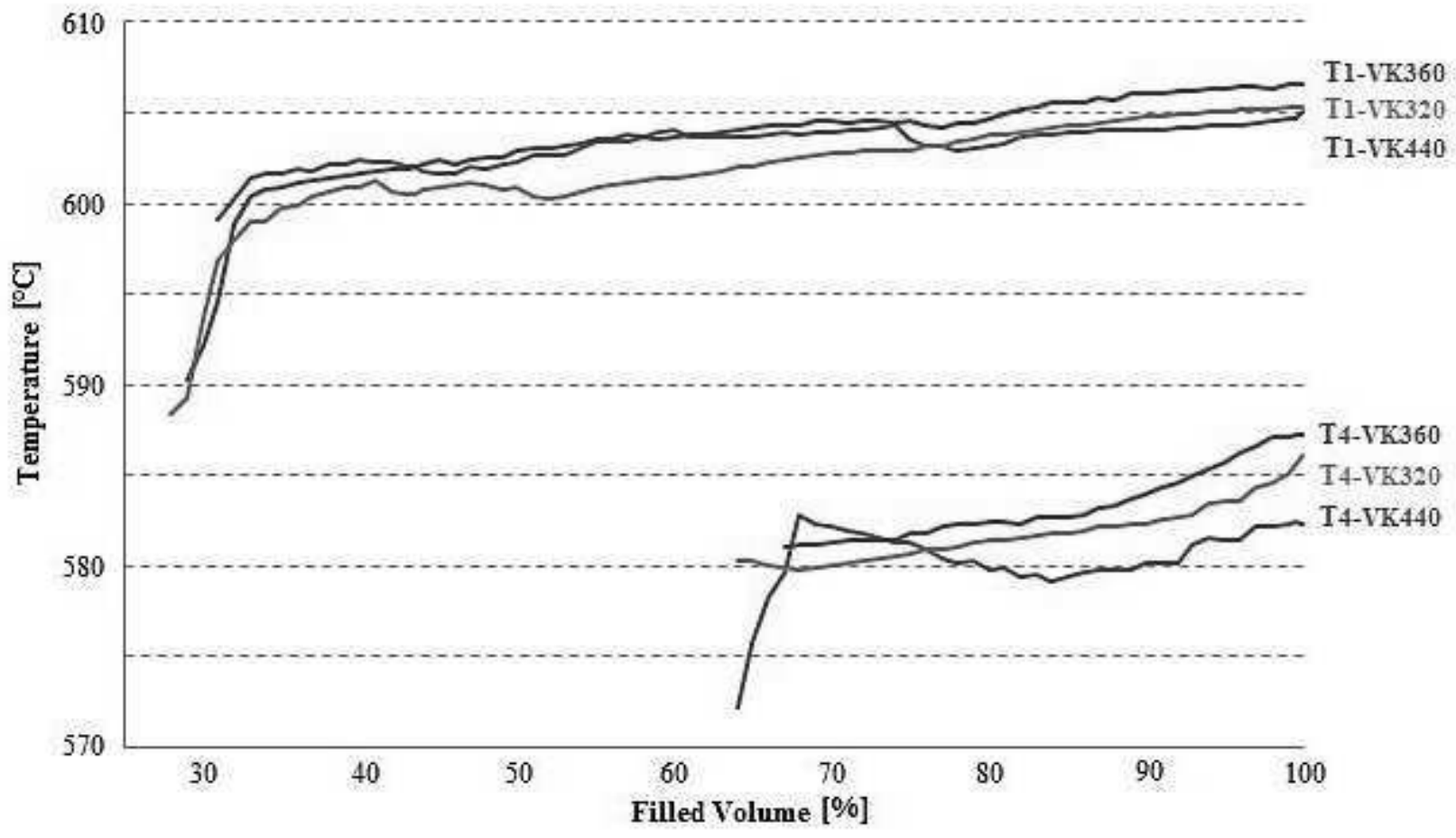

Fig. 4 Melt temperature during the filling

It should be noted that the melt flow front is formed by a firstly solidificated layer of oxidized metal, which after the transition through the cast is being retained by the owerflows. The measuring point is after the transition supplied by a new melt from the filling chamber and thus carries a higher temperature. The value of the melt flow face is therefore indicative of the temperature range in which the mel tis present during the filling.

\section{Analysis of the melt flow velocity in the runner}

Since the experiments describing the temperature states of the melt during the transition through runners disproved the initial assumtion of higher thermal capacity, the authors focused on the melt velocity assessment and the associated filling time.

In order to ensure the results of velocities with the assumtion of laminar flow, the measuring points $1 . \mathrm{A} / 1$. B and $4 . \mathrm{A} / 4$. B were excluded because due to the geometry of the gating system occured the turbulences and swirling of the melt. Velocities in the points 2.A/2.B and 3.A/3.B were considered only in the state in which the melt filled $100 \%$ of the cross section of the runner in the measurement point. In $\boldsymbol{T a b}$. 6 the velocity values in the runner are stated.
Tab. 6 The runner melt velocity values

\begin{tabular}{|c|c|c|c|}
\hline \multicolumn{4}{|c|}{ MELT VELOCITY IN RUNNER $v_{R}\left[\mathrm{~m}_{.} \mathrm{s}^{-1}\right]$} \\
\hline \multirow{2}{*}{ Runner no. } & \multicolumn{2}{|c|}{ MEASURING POINT } & \multirow[t]{2}{*}{ Mean } \\
\hline & 2 & 3 & \\
\hline 1. VK440 & 27.25 & 23.74 & 25.50 \\
\hline 5. VK360 & 31.01 & 25.12 & 28.06 \\
\hline 7. VK320 & 32,04 & 26,11 & 29.07 \\
\hline
\end{tabular}

With the decreasing cross section of the runner while maintaining a constant mass flow rate $Q_{m}$ the melt flow velocity in the runner $v_{R}$ increases, thereby shortening the filling time of the mold cavity. Tab. 7 shows the filling times of the mold cavity of individual gating systems acquired by simulation.

Tab. 7 Mold cavity filling time values

\begin{tabular}{|l|l|}
\hline MOLD CAVITY FILLING TIME \\
\hline Runner no. & Filling Time $\boldsymbol{t}$ [s] \\
\hline 1. VK440 & 0.029 \\
\hline . VK420 & 0.028 \\
\hline 3. VK400 & 0.028 \\
\hline 4. VK380 & 0.027 \\
\hline 5. VK360 & 0.026 \\
\hline 6. VK340 & 0.026 \\
\hline 7. VK320 & 0.025 \\
\hline
\end{tabular}




\section{Analysis of results}

As demonstrated, the most advantageous temperature ratios of the melt before entering the gate were reached by the gating system No. 5 VK360, with dimensions of the runners according to the $\boldsymbol{T a b} .3$.

The assumption that the best temperature characteristics will be achieved by the reference gating system No. 1 VK440 has been disproved. The explanation could be in the reference on the melt flow velocity in runner and associated mold filling time. Although the VK440 gating system has the largest volume and heat capacity of the melt, it has also a larger casting surface and the melt in the mold until its completely filled remains longer. The longer filling time of the mold cavity allows the greater influence of the melt undercooling due to the contact with the mold face. At the same time, the larger surface of the runners generates larger heat exchange surface and thus allows more intense heat transfer and melt discharge into the mold.

In the runner No. 5 VK360 an optimal ratio was reached between the temperature capacityin the melt volume and the melt flow velocity.

Conversely, the melt in runner No.7 VK320, although having the highest velocity and remaining in the runner the shortest time, does not reach the highest temperatures. This could be due to the low melt volume in the runners, and thus to the sub-cooling due to lower heat capacity in the melt volume.

It is also worth noting that the temperature drops between measuring points $3 . \mathrm{A} / 3 . \mathrm{B}$ and $4 . \mathrm{A} / 4$.B. This phenomenon is not only due to the fact that the measuring points $4 . \mathrm{A} / 4$. B have the largest average length of the melt flow $l_{54}$ and are therefore at the most distant point of the runner. The above mentioned temperature drop is caused by the measuring point. Measuring points 1 .A/1.B to 3.A/3.B are located inthe zone that is heat affected by the heat transfer from the main runner to the mold, wherein 4.A/4.B is in zone that is not affected, and hence, is more subcooled by the influence of the temperature of the mold. Thus, it is possible to formulate a statement that when the ingate is located in a zone of the of heat affected mold by the main runner, the temperature drop due to the length of the runner is not remarkable.

\section{Conclusion}

Presented contribution deals with the optimization of the numerical design of the gating system using simulation program. The optimization was focused on the dimensions of the runners in order to achieve filling of the mold cavity by the melt reaching the highest possible temperature, keeping the constant input parameters settings.

After the simulation and evaluation of the considerated parameters, The VK360 gating system was the optimal solution for the runners. As has been shown, this solution provides the best ration between the temperature capacity in the melt volume and the melt flow velocity. On the basis of the optimization, shortening of the mold filling time was also achieved. For comparison, the time of one casting cycle from the start of the casting to the complete solidification of the cast was by the reference gating system No. 1 VK440 $t_{c 440}=$ $18,478 \mathrm{~s}$ and by gating system No. $5 t_{c 360}=16,983 \mathrm{~s}$. Another noteable fact is the reduction of the volume of the gating system. If the volume of the runners by gating system VK440 was $351027.165 \wedge 10^{-9} \mathrm{~m}^{3}$, by optimization of the gating system VK360 was achieved volume of the runners $288331,609^{\wedge} 10^{-9} \mathrm{~m}^{3}$. The ultimate impact of the optimization is therefore also increase in production efficiency by shortening the casting cycles $t_{c}$ and economical saving in the volume of waste produced or the return material reduction of the gating system volume.

It is clear that CAD/CAM support in the foundry area has an irreplaceable and important place. Although some of the smaller foundries are still hampered by the implementation of simulations in the technical preparation of production and rely on the experience of the main technologists. It is the implementation of simulation programs that, despite the higher purchase price, can lead to a significant increase in production efficiency and increased competitivness in the market, with the associated economic profit.

\section{Acknowledgement}

This paper has been prepared within the project $V E G A$ 1/0041/16.

\section{References}

[1] ČSN 228601. Formy tlakové licí. Zásady pro navrhování.. Praha: Vydavatelství Úřadu pro normalizaci a měření, 1984. 32 p.

[2] North American Die Casting Association: Gating Manual, Wheeling: NADCA, 2006

[3] GAŠPÁR, Š., PAŠKO, J., MAJERNÍK, J. (2017). Influence of Structure Adjustment of Gating System of Casting Mould upon the Quality of Die Cast. 1st ed. Lüdenscheid: RAM - Verlag, 2017. 82 p. ISBN 978-3-942303-47-7.

[4] MAJERNÍK, J., KARKOVÁ, M., KMEC, J. (2017). Issue of Design Gate Dimensions and Experimental Assessment of the Suitability of Analytical Design. Key Eng. Mater., 2017, vol. 756, p. 142-148. ISSN 1662-9795.

[5] MAJERNÍK, J., KMEC, J., KARKOVÁ, M. (2017). Critical Runner Length as a Constraining Factor in Gating System Design. MM SCIENCE JOURNAL, 2017, December 2017, p. 1929-1932. ISSN 1803-1269.

[6] MAJERNÍK, J., KMEC, J., KARKOVÁ, M. (2017). Analysis of the Impact of the Construction of a Gate on the Macroscopic Structure of a Casting and Its Influence on the Mechanical Properties of Castings. Manufacturing Technology, 2017, vol. 17, no. 1, p. 62-66. ISSN 1213-2489. 
[7] MAJERNÍK, J., KMEC, J., et al. (2017). The Use of Simulation Programmes for the Structural Analysis and Engineering Optimization of Gating System Structures for Use with High Pressure Die Casting Technology. Manufacturing Technology, 2017, vol. 17, no. 3, p. 343-347. ISSN 1213-2489.

[8] MAJERNÍK, J., KMEC, J., et al. (2017). Analysis of Influence Dimensions of the Gate on the Homogeneity of the Low Weight Castings Made of Silumin. Manufacturing Technology, 2017, vol. 17, no. 4, p. 499-502. ISSN 1213-2489.

[9] PAŠKO, J. (2010). Die Casting Plunger Pressing Velocity and Analysis of Its Influence on a Permanent Deformation Value of a Casting Made from an ENAC 47100 Alloy. Manufacturing Technology, 2010, vol. 10, p. 23-26. ISSN 1213-2489.
[10] PETI, F. - GRAMA, L. - SOLOVASTRU, L. CORB, C. (2010). Studies concerning the design of the runner, gate and venting systems in the case of the high pressure die casting technology. In: Fascicle of Management and Technological Engineering. Vol. 29, No. 9/2010, p. 3177-3183, ISSN 1583-0691.

[11] KALINCOVÁ, D., ŤTAVODOVÁ, M., KUŚMIERCZAK, S. (2017). Analysis of the Properties Aluminium Casting Motorcycle Forks Arm after Compression Test. Manufacturing Technology, 2017, vol. 17, no. 5, p. 717-722. ISSN 1213-2489.

[12] MAŠČENIK, J. (2012). The evacuation of pressure moulds as progressive developments of die casting process, In: Acta Technica Corviniensis : Bulletin of engineering. Vol. 5, no. 3 (2012), p. 2526. - ISSN 2067-3809 